\title{
Actin Plays a Role in Both Changes in Cell Shape and Gene- Expression Associated with Schwann Cell Myelination
}

\author{
Cristina Fernandez-Valle, ${ }^{1}$ Douglas Gorman, ${ }^{3}$ Anna M. Gomez, ${ }^{1}$ and Mary Bartlett Bunge ${ }^{1,2,3}$ \\ 1 The Chambers Family Electron Microscopy Laboratory, The Miami Project to Cure Paralysis, and Departments of \\ Neurological Surgery and ${ }^{2}$ Cell Biology and Anatomy, University of Miami School of Medicine, Miami, Florida 33136, and \\ ${ }^{3}$ Department of Neurobiology and Anatomy, Washington University School of Medicine, St. Louis, Missouri, 63110
}

Schwann cell (SC) differentiation into a myelinating cell requires concurrent interactions with basal lamina and an axon destined for myelination. As SCs differentiate, they undergo progressive morphological changes and initiate myelin-specific gene expression. We find that disrupting actin polymerization with cytochalasin D (CD) inhibits myelination of SC/neuron cocultures. Basal lamina is present, neurons are healthy, and the inhibition is reversible. Electron microscopic analysis reveals that actin plays a role at two stages of SC differentiation. At $0.75-1.0 \mu \mathrm{g} / \mathrm{ml} \mathrm{CD}$, SCs do not differentiate and appear as "rounded" cells in contact with axons. This morphology is consistent with disruption of actin filaments and cell shape changes. However, at $0.25 \mu \mathrm{g} / \mathrm{ml} \mathrm{CD}$, SCs partially differenti- ate; they elongate and segregate axons but generally fail to form one-to-one relationships and spiral around the axon. In situ hybridizations reveal that SCs in CD-treated cultures do not express mRNAs encoding the myelin-specific proteins $2^{\prime}, 3^{\prime}-$ cyclic nucleotide phosphodiesterase (CNP), myelin-associated glycoprotein (MAG), and PO. Our results suggest that the lower CD dose, SCs commence differentiation as evidenced by changes in cell shape but are unable to elaborate myelin lamellae because of a lack of myelin-specific mRNAs. We propose that F-actin influences myelin-specific gene expression in SCs.

Key words: Schwann cells; myelination; actin; cytochalasin D; mRNA expression; in situ hybridization
In the animal, Schwann cells (SCs) differentiate into a myelinating phenotype on contact with an axon destined for myelination (deWebster, 1971; Weinberg and Spencer, 1975; Aguayo et al., 1976a,b). The axonal and SC molecules involved in this inductive event remain unknown. However, it is clear from results of in vitro experiments that axon-SC interactions alone are insufficient to induce SC myelination. Adhesion of SCs to basal lamina is also required for myelin-specific gene expression and myelination (Carey and Todd, 1987; Eldridge et al., 1989, Fernandez-Valle et al., 1993) (for review, see Bunge, 1993). Myelination in vitro can be inhibited or promoted by removing or adding ascorbate to serum-containing medium (Eldridge et al., 1987). Ascorbate allows basal lamina deposition by promoting synthesis and secretion of triple-helical type IV collagen, which forms a scaffold for basal lamina assembly by binding extracellular matrix components, including laminin (Woodley et al., 1983).

Evidence suggests that laminin, present in basal lamina, interacts with SC receptors to initiate signal transduction cascades necessary for differentiation. Addition of soluble laminin, but not type IV collagen or heparan sulfate proteoglycan, to medium lacking ascorbate supports SC myelination (Eldridge et al., 1989). Recent data obtained using a function-blocking anti- $\beta 1$ integrin

\footnotetext{
Received June 7, 1996; revised Sept. 18, 1996; accepted Oct. 18, 1996.

This work was supported by National Institutes of Health Grant NS09923 to R.P.B., the State of Florida, and The Miami Project to Cure Paralysis. We thank A. Feucht, E. Cuervo, and M. Bates for technical assistance; R. Camarena for photographic reproduction; Drs. J. Brockes and M. Schachner for antibodies; Drs. M. Gravel, G. Lemke, and J. Salzer for cDNAs; and Drs. P. Wood and K. Carraway for valuable comments.

Correspondence should be directed to Dr. Cristina Fernandez-Valle at her current address: Department of Molecular Biology, Biol. 330, University of Central Florida, Orlando, Florida 32816-2360.

In memory of Richard Paul Bunge, April 15, 1932-September 10, 1996.

Copyright (C) 1996 Society for Neuroscience $0270-6474 / 96 / 160241-10 \$ 05.00 / 0$
}

antibody suggest that a $\beta 1$ integrin is essential for myelination (Fernandez-Valle et al., 1994b). In the presence of this anti- $\beta 1$ antibody, basal lamina fails to adhere to the SC surface, suggesting that functional integrins are necessary for binding basal lamina and initiating signaling cascades necessary for myelination. Undifferentiated SCs express two $\beta 1$ integrins, $\alpha 1 \beta 1$ and $\alpha 6 \beta 1$ (Einheber et al., 1993, Feltri et al., 1994; Fernandez-Valle et al., 1994b; Niessen et al., 1994) that bind laminin (Sonnenberg et al., 1990).

On binding their native ligands, integrins initiate signal transduction cascades that affect cellular behavior and gene expression in many cell types (Werb et al., 1989; Kornberg et al., 1991; Kornberg and Juliano, 1992; Yurochko et al., 1992; Juliano and Haskill, 1993; Lin and Bissell, 1993). Association of $\beta 1$ integrins with actin is an integral part of $\beta 1$ integrin-dependent signaling (Horwitz et al., 1986; Otey et al., 1990; Shaw et al., 1990; Lipfert et al., 1992; Schaller et al., 1992; Clark and Brugge, 1995; Miyamoto et al., 1995). Actin is now viewed as a dynamic molecule that through associations with other proteins dictates localization of signal transduction molecules (Carraway and Carraway, 1995; Mochly-Rosen, 1995) that relay information from surface receptors. Actin, thereby, plays a role in mediating cellular responsiveness to the environment.

In this study, we demonstrate that actin plays two distinct and necessary roles during SC differentiation; one in mediating cell shape changes and another in influencing myelin gene expression. Abundant expression of mRNAs encoding myelin proteins can be blocked with low cytochalasin D (CD) concentrations that do not inhibit morphological changes occurring early during SC differentiation. This work suggests that F-actin influences myelinspecific gene expression in SCs. Preliminary reports have appeared in abstract form (Gorman and Bunge, 1988a,b; Fernandez-Valle et al., 1994a). 

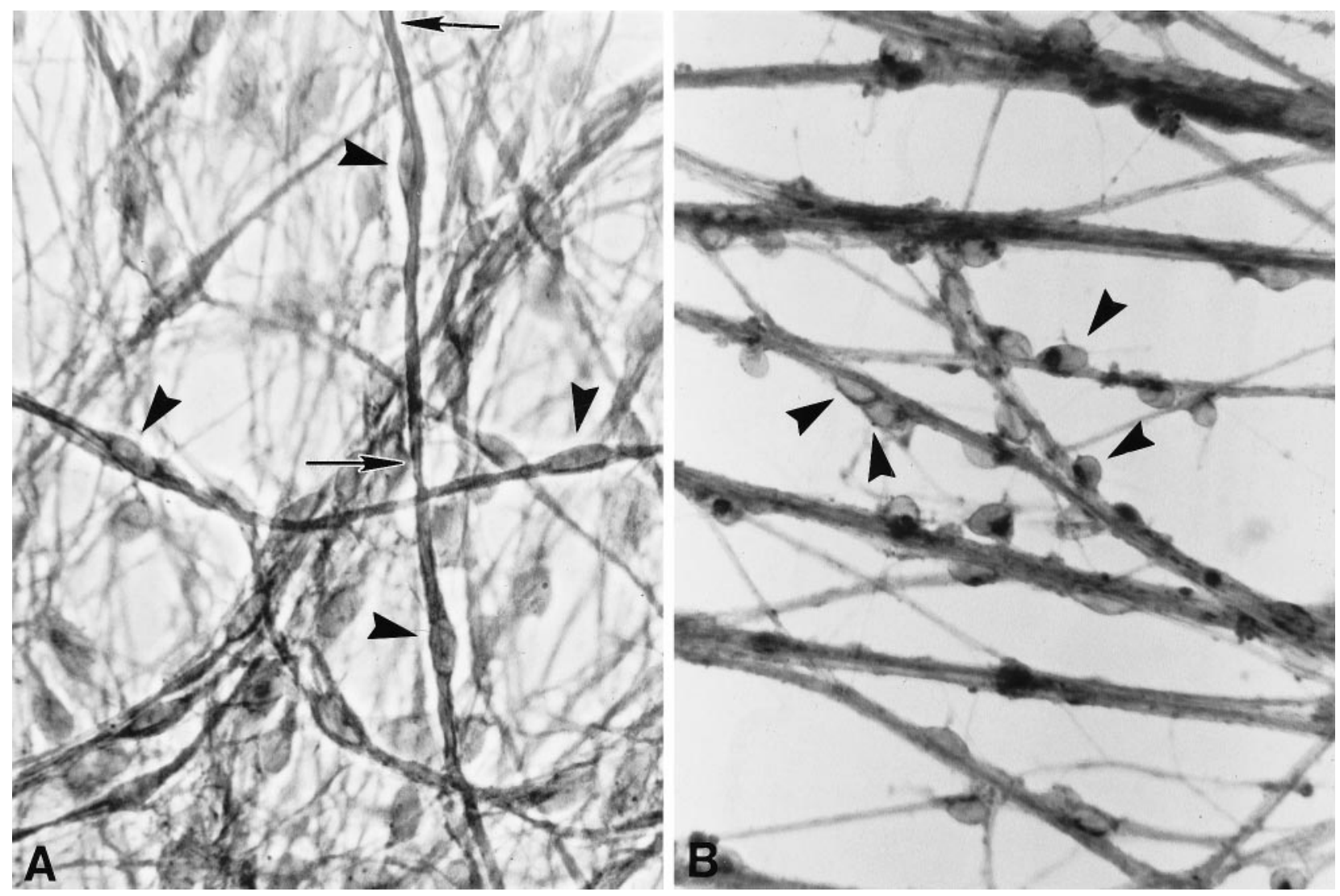

Figure 1. CD inhibits Schwann cell differentiation on collagen. SC-sensory neurons cultures were grown for 1 week in myelination-permissive medium alone $(A)$ or with $1 \mu \mathrm{g} / \mathrm{ml} \mathrm{CD}(B)$. Sudan black staining used to visualize myelin revealed that SCs (arrowheads) in control cultures $(A)$ had flattened and elongated along axons and were beginning to form myelin (between arrows). SCs grown in the presence of $\mathrm{CD}(B)$ failed to elongate in association with axons, retained a rounded morphology, and did not myelinate axons. Magnification, $800 \times$.

\section{MATERIALS AND METHODS}

\section{Tissue culture}

Primary SC cultures. SCs were isolated from sciatic nerves removed from E21 or newborn Sprague Dawley rats (Charles River, Raleigh, NC) and expanded in vitro with medium containing DMEM, $10 \%$ heat-inactivated fetal bovine serum (FBS, Life Technologies, Grand Island, NY), forskolin, and pituitary extract (BTI, Stoughtan, MA) on poly-L-lysine- (Sigma, St. Louis, MO) coated $100 \mathrm{~mm}$ tissue culture dishes (Brockes et al., 1979). SC cultures were passaged no more than three times before plating SCs onto sensory neuron cultures. SCs used in cultures grown on collagen (see Figs. 1-3, 5) were prepared as in Eldridge et al. (1987).

$S C$-neuron co-cultures. Neurons were isolated from cervical dorsal root ganglia of Sprague Dawley rat embryos at $15 \mathrm{~d}$ gestation by dissociation with trypsin. Cultures grown on collagen (see Figs. 1-3,5) were prepared as described in Eldridge et al. (1987). Myelination-permissive medium for these experiments consisted of Eagle's minimum essential medium (EMEM), 15\% FBS, and 10\% chick embryo extract. The culture substratum was changed from collagen to laminin, because laminin is compatible with in situ hybridization techniques. Cultures grown on collagen routinely detach during the prehybridization period. Cultures used (see Figs. 4, 6, and 7 were grown on laminin as in Fernandez-Valle et al. (1993). Myelination-permissive medium in these experiments consisted of EMEM, 15\% heat-inactivated FBS, nerve growth factor (NGF), and 50 $\mu \mathrm{g} / \mathrm{ml}$ ascorbate.

$C D$ treatment. Cultures of SCs and neurons were grown in medium that does not support myelination either alone or together for 2 weeks to expand the SC population on axons. All cultures at this time have equivalent SC densities. Cultures were then fed myelination-permissive medium with or without $\mathrm{CD}$ at $0.25,0.50,0.75$, or $1.0 \mu \mathrm{g} / \mathrm{ml}$. CD (Sigma) was prepared as a $1 \mathrm{mg} / \mathrm{ml}$ stock in DMSO and then further diluted in medium as indicated. In some experiments, matrigel (Collaborative Research, Lexington, MA) was diluted 1:100 in CDcontaining myelination-permissive medium. Medium was replenished every other day until myelin became visible in the control cultures ( 7-8 d). Cultures were processed for cytochemistry, electron microscopy (EM), or in situ hybridization. Standard cultures typically contained 1000 neurons and $\sim 240,000$ SCs. For additional details of the culture procedure, see Kleitman et al. (1991).

\section{Cytochemistry and EM}

Immunostaining. Cultures were rinsed with several changes of PBS and fixed in $4 \%$ paraformaldehyde for $10 \mathrm{~min}$. For detection of $2^{\prime}, 3^{\prime}$-cyclic nucleotide phosphodiesterase (CNP), myelin-associated glycoprotein (MAG), and P0, cultures were permeabilized with $0.5 \%$ Triton X-100 in $4 \%$ paraformaldehyde for $10 \mathrm{~min}$, followed by exposure to a series of $50 / 100 / 50 \%$ acetone for $5 \mathrm{~min}$ each at $-20^{\circ} \mathrm{C}$. Cultures were rehydrated and incubated for $30 \mathrm{~min}$ in $10 \%$ goat serum/PBS. The antibodies used were a P0 antiserum (1:100, courtesy of J. Brockes), anti-CNP (1:100, Sigma), anti-MAG (undiluted hybridoma medium, courtesy of $\mathrm{M}$. Schachner). Control staining was carried out by omitting the primary antibody. Cultures were rinsed three times for $5 \mathrm{~min}$ each in goat serum/PBS and then incubated in a 1:100 dilution of either rhodamine or fluorescein goat anti-mouse or goat ant-rabbit (Organon Teknika, West Chester, PA) for an additional $30 \mathrm{~min}$. Cultures were rinsed three to five times in PBS, post-fixed in $4 \%$ paraformaldehyde/PBS for $5 \mathrm{~min}$, and mounted in Citifluor mounting medium (Citifluor Products, Canterbury, UK) containing Hoechst dye 33342 (Sigma). Cultures were viewed on a Zeiss universal microscope equipped with fluorescence optics.

Phalloidin staining. Cultures were rinsed several times with $0.1 \mathrm{M}$ sodium phosphate buffer $\left(\mathrm{PO}_{4}\right)$ and fixed in $4 \%$ paraformaldehyde for 10 min. To disrupt extracellular matrix to increase phalloidin penetration, cultures were permeabilized in $4 \%$ paraformaldehyde $/ 0.1 \%$ Triton X-100 for $30 \mathrm{~min}$ and then were rinsed with $\mathrm{PO}_{4}$ and incubated for $20 \mathrm{~min}$ in $\mathrm{PO}_{4}$ containing $3 \mu \mathrm{M}$ rhodamine-conjugated phalloidin (Molecular Probes, Eugene, OR). Cultures were rinsed in $\mathrm{PO}_{4}$ and mounted in 


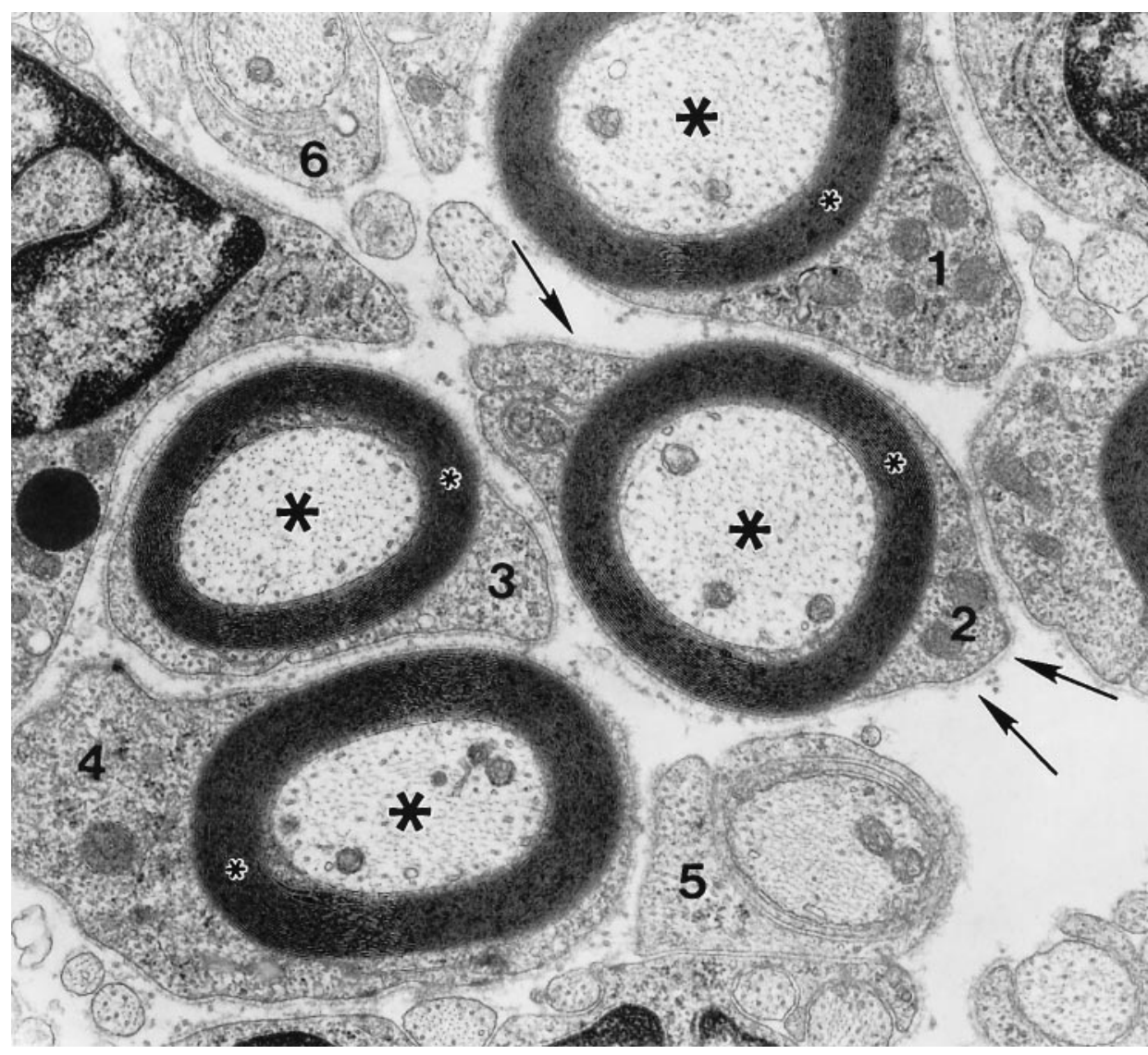

Figure 2. Schwann cells cultured in myelination-permissive medium rapidly differentiate to myelin-forming cells. This electron micrograph reveals the degree of SC differentiation achieved during 1 week in culture. Four SCs (1-4) elaborated up to 25 myelin lamellae (small asterisks) around axons (large asterisks). Each SC-axon unit is surrounded by a complete basal lamina (arrows). Two SCs $(5,6)$ at earlier stages of differentiation have begun to spiral around smaller diameter axons. Magnification, 30,000×.
Citifluor mounting medium (Citifluor Products) containing Hoechst dye 33342 (Sigma).

Sudan black staining and quantitation. Cultures were fixed for $1 \mathrm{hr}$ in $4 \%$ paraformaldehyde in $\mathrm{PO}_{4}$, rinsed several times with $\mathrm{PO}_{4}$, and osmicated in $1 \%$ osmium tetroxide $/ \mathrm{PO}_{4}$ for an additional hour. Co-cultures were dehydrated in 25,50 , and $70 \%$ ethanol for $5 \mathrm{~min}$ each and stained with $0.5 \%$ Sudan black in $70 \%$ ethanol for $1 \mathrm{hr}$. Co-cultures were destained for $10-30 \mathrm{~min}$ in $70 \%$ ethanol, rehydrated in 50 and $25 \%$ ethanol followed by $\mathrm{PO}_{4}$, and then mounted in glycerin jelly. Quantitation was carried out by viewing co-cultures under $400 \times$ magnification and counting the number of myelin segments that intersected a reference line per field; 15 fields per co-culture were examined in this manner, and two to five cultures were examined per group.

$E M$. Co-cultures were fixed in buffered glutaraldehyde followed by osmium tetroxide, dehydrated in ethanol, and embedded in Embed (EMS, Fort Washington, PA) (Ratner et al., 1986). Areas for examination were selected, thin-sectioned, and stained with uranyl acetate and lead citrate. Sections were viewed with a Philips CM10 electron microscope.

\section{In situ hybridization}

RNA probe preparation. A rat $\mathrm{P} 0$ cDNA was kindly provided by $\mathrm{G}$. Lemke (Lemke and Axel, 1985), and RNA probes were prepared as in Fernandez-Valle et al. (1993). A BlueScript vector containing rat CNP2 cDNA was kindly provided by M. Gravel (Gravel et al., 1994). It was linearized with Bam HI and transcribed using T7 polymerase to generate antisense probes. A BlueScript vector containing S-MAG cDNA was kindly provided by J. Salzer (Salzer et al., 1987). It was linearized with SalI and transcribed using T3 polymerase to generate antisense probes. Digoxigenin-labeled antisense and sense RNA probes were synthesized by in vitro transcription using Genius4 (Boehringer Mannheim, Indianapolis, IN). Full-length probes were reduced to 200-400 nucleotides by alkaline hydrolysis. Samples of full-length and hydrolyzed probes and a neomycin control RNA were electrophoresed through formaldehyde agarose gels to verify the sizes, transferred to nitroplus membranes, and detected immunocytochemically using an antibody against digoxigenin coupled to alkaline phosphatase (AP). The amount of RNA synthesized was quantitated by dot-blotting, using standard procedures as described by the manufacturer.

Hybridization. Cultures were treated as described in Fernandez-Valle et al. (1993). Hybrids were detected by incubating cultures in a solution containing nitro-blue tetrazolium and 5-bromo-4-chloro-3-indoyl phosphate in $100 \mathrm{~mm}$ of Tris $\mathrm{HCl}, \mathrm{pH} 9.5,50 \mathrm{~mm}$ of $\mathrm{MgCl}_{2}$, and $100 \mathrm{mM} \mathrm{NaCl}$ with $10 \%$ polyvinyl alcohol, 31,00-50,000 MW (Aldrich, Milwaukee, WI) for 1-5 hr at room temperature (Barth and Ivarie, 1994). To stop the AP reaction, cultures were rinsed in $10 \mathrm{~mm}$ Tris $\mathrm{HCl}, \mathrm{pH}$, with 1 mM EDTA. For each of the three digoxigenin-labeled sense and antisense RNA probes used, the incubation time in AP substrate solution varied between RNA probes because of differences in message abundance in myelinating cultures. Incubation in substrate solution for all cultures hybridized with the identical RNA probe was terminated when the myelinating antisense sample reached a maximum intensity. This time varied from $1 \mathrm{hr}$ when using the P0 RNA probe to $3 \mathrm{hr}$ when using the MAG RNA probe. Cultures were additionally fixed in $4 \%$ paraformaldehyde to preserve the reaction product, mounted in a glycerol/PBS solution (Citifluor, Canterbury), and viewed by differential interference contrast microscopy.

\section{RESULTS}

\section{CD inhibits elongation and myelination in a dose-dependent manner}

SC-sensory neuron cultures were maintained in myelinationpermissive medium in the absence or presence of various $C D$ concentrations. Cultures were divided in two; one-half was stained with Sudan black, and the other half was processed for EM. In control cultures, myelin was evident after 1 week in myelinationpermissive medium (Fig. 1A). Cultures grown for 1 week in the same medium but containing $1 \mu \mathrm{g} / \mathrm{ml} \mathrm{CD}$ remained undifferentiated (Fig. $1 B$ ). SCs adhered to axon fascicles but were rounded and did not undergo the characteristic elongation into a bipolar cell that heralds initiation of SC differentiation. As the CD concentration was reduced to 0.75 and $0.50 \mu \mathrm{g} / \mathrm{ml}$, inhibition of cell 

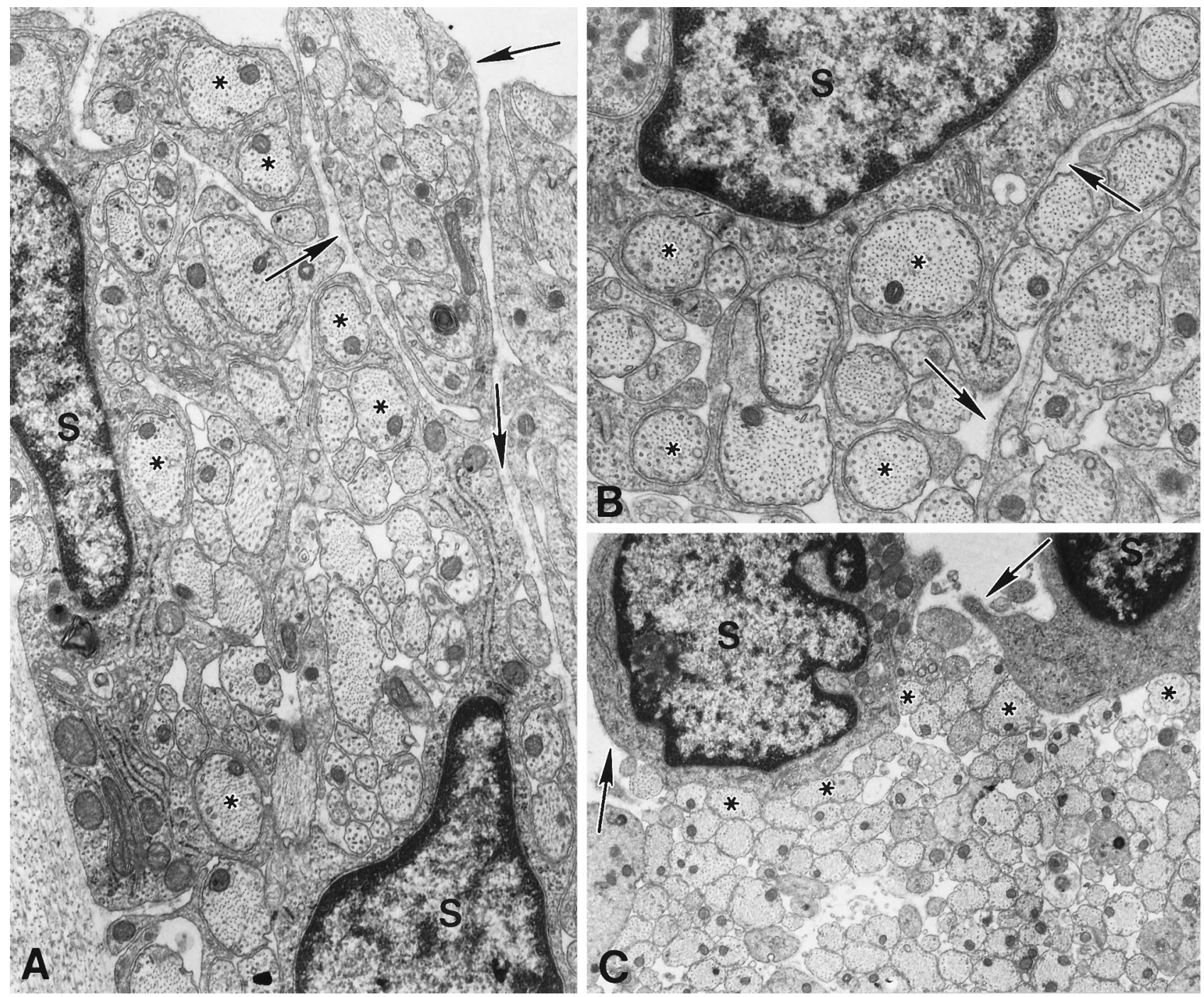

Figure 3. CD causes a dose-dependent disruption of morphological differentiation; elongation and spiralization are selectively inhibited by different CD concentrations. SCs were cultured in myelination-permissive medium containing $0.5(A), 0.75(B)$, or $1.0 \mu \mathrm{g} / \mathrm{ml}(C) \mathrm{CD}$ for 1 week. At the lowest $\mathrm{CD}$ concentration $(A)$, SCs $(S)$ elongated and extended multiple processes into axonal fascicles, thereby segregating axons into smaller groups or isolating them completely. Continuing spiralization around an individual axon was not observed. At the intermediate CD concentration $(B)$, SCs retained the ability to extend processes and segregate axons into smaller groups. However, at the highest CD concentration $(C)$, SCs remained rounded, adhered to axons (asterisks) but did not extend processes into axonal fascicles. Basal lamina (arrows) assembled and attached to the SC surface in all CD doses. Magnification: $A, 25,000 \times, B, 35,000 \times, C, 15,000 \times$

shape change was reduced, and increasing numbers of SCs displayed morphologies indicative of a differentiating or "promyelinating" phenotype. An occasional myelin segment was observed at these lower CD concentrations. Cultures were systematically scanned, and the number of myelin segments present in each half culture was quantitated (Table 1).

Because SCs undergo progressive changes in morphology as they differentiate, the extent to which differentiation was achieved in the presence of $\mathrm{CD}$ can be determined using ultrastructural analysis of SC morphology. SCs were studied for indications of axonal adhesion, elongation, one-to-one relations, spiralization, and myelination. In control cultures, the maximum level of differentiation achieved by SCs after 1 week in myelinationpermissive medium was the elaboration of 20 to 25 myelin lamellae (Fig. 2). The ability of SCs to differentiate, as evidenced by morphology, was inhibited in a dose-dependent manner by incubation in CD for 1 week. SCs in cultures maintained in $0.5 \mu \mathrm{g} / \mathrm{ml}$
CD had elongated along axons and segregated axonal segments but generally did not form a 1:1 relationship with axons or extend multiple membrane spirals to form myelin (Fig. 3A). SCs in cultures maintained in $0.75 \mu \mathrm{g} / \mathrm{ml}$ also elongated and extended processes into axonal fascicles but again failed to form 1:1 relationships with axons (Fig. 3B). SCs in cultures maintained in the presence of $1 \mu \mathrm{g} / \mathrm{ml} \mathrm{CD}$ neither elongated along axons nor extended processes into axonal fascicles (Fig. $3 C$ ). Perturbation of actin polymerization dynamics achieved with lower $\mathrm{CD}$ concentrations was associated with a failure to form 1:1 relationships with axons but not in elongation, whereas higher $\mathrm{CD}$ concentrations inhibited SC elongation and thereby precluded further differentiation.

The ability of SCs to assemble basal lamina when incubated with $\mathrm{CD}$ was also studied at the ultrastructural level. We found that basal lamina was present in CD-treated cultures, regardless of the drug concentration used. The amount of basal lamina, 

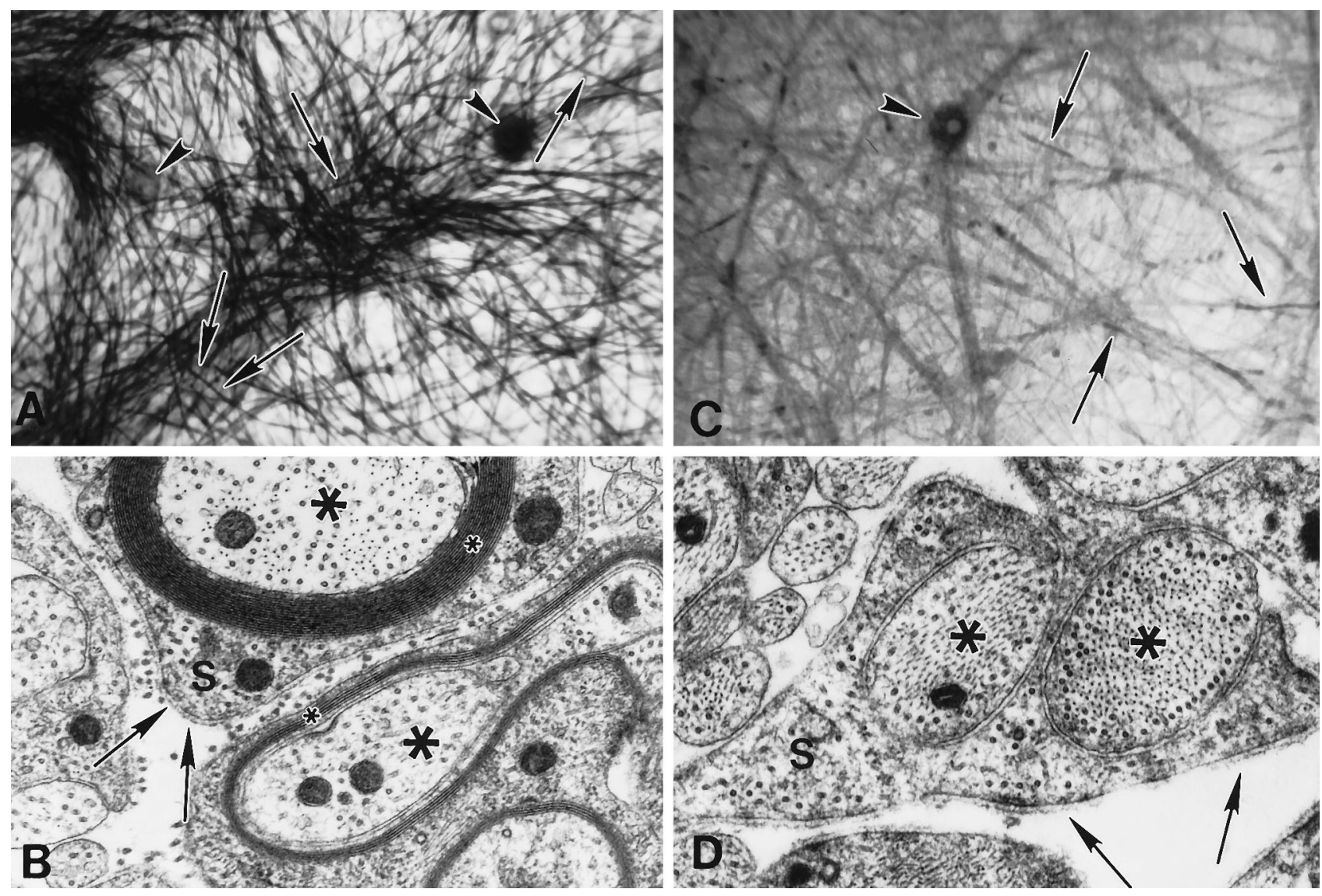

Figure 4. Lower CD concentrations inhibit myelin formation in cultures grown on laminin instead of collagen. Cultures grown in myelination-permissive medium alone $(A, B)$ or with $\mathrm{CD}, 0.25 \mu \mathrm{g} / \mathrm{ml}(C, D)$ are illustrated. Sudan black staining $(A, C)$ demonstrates that myelin (arrows) is abundant in control cultures but is generally absent in CD-treated cultures, although SCs elongate along axons. Neuron cell bodies are indicated by arrowheads. EM confirms that in myelination-permissive medium $(B)$, SCs $(S)$ differentiate and form myelin (small asterisks). In CD-treated cultures $(D)$, myelin is absent, but basal lamina is present (arrows). SCs retain the ability to segregate axons (large asterisks) but cannot spiral membrane around the axon to form myelin lamellae in $0.25 \mu \mathrm{g} / \mathrm{ml} \mathrm{CD}$. Magnification: $A, C, 166 \times ; B, D, 40,000 \times$.

however, was less in CD-treated cultures than in controls (compare Figs. 2 and 3 and Fig. 4, $B$ and $D$ ). Although extracellular matrix abundance increases as differentiation proceeds and basal lamina is not expected to be continuous until many myelin lamellae have formed, we tested the possibility that inhibition of myelination was attributable to an unrecognized effect of $\mathrm{CD}$ on extracellular matrix production. Exogenous basal lamina components in the form of matrigel were added along with $\mathrm{CD}$ to cultures grown in myelination-permissive medium. Addition of matrigel did not override CD's inhibitory effect on myelination

\section{Table 1. Quantitation of myelin segments in SC/neuron cultures grown} on collagen

\begin{tabular}{llcc} 
& $\begin{array}{l}\text { No. of fields } \\
\text { counted }\end{array}$ & \multicolumn{2}{c}{ Myelinated segments } \\
\cline { 3 - 4 } Conditions & 53 & Per sample & Per $\mathrm{mm}^{2}$ \\
\hline $\mathrm{MM}$ & 63 & 2050 & 206 \\
$\mathrm{MM}+\mathrm{DMSO}$ & 73 & 1934 & 178 \\
$\mathrm{MM}+0.75 \mu \mathrm{g} / \mathrm{ml} \mathrm{CD}$ & 70 & 2 & 0 \\
${ }^{*} \mathrm{MM} \rightarrow 0.75 \mu \mathrm{g} / \mathrm{ml} \mathrm{CD}$ & 7305 & 108 \\
$* \mathrm{MM}+0.75 \mu \mathrm{g} / \mathrm{ml} \rightarrow \mathrm{MM}$ & 71 & 164 & 13
\end{tabular}

MM, Myelination-permissive medium.

${ }^{*}$ Cultures were grown for $7 \mathrm{~d}$ in the first medium and for an additional $7 \mathrm{~d}$ in the second medium. Values are derived from single cultures. (data not shown). Therefore, it is unlikely that myelination was inhibited because of nonspecific effects of $\mathrm{CD}$ on extracellular matrix secretion or assembly.

To determine whether myelin-specific mRNAs were expressed by SCs in CD-treated cultures using in situ hybridization techniques, the culture substratum was changed from collagen to laminin, which is stable during the procedure. We repeated the experiments presented above to verify that this change in substratum did not alter the results. Three to five cultures per group from at least four separate experiments were treated with various $C D$ concentrations for $7 \mathrm{~d}$ and stained with Sudan black, and myelin sheaths were quantitated (Table 2, Fig. 4A,C). Separate cultures were used for EM analysis (Fig. 4B,D). The results demonstrated that the inhibitory effect of $\mathrm{CD}$ on myelination was also observed when cultures were grown on laminin and, moreover, that lower $\mathrm{CD}$ concentrations led to the results observed when collagen served as the substratum. One-to-one ensheathment of axons was essentially inhibited by $0.25 \mu \mathrm{g} / \mathrm{ml}$ CD. The DMSO-treated controls were myelinated to the same extent as untreated controls. The number of myelin internodes present in control cultures varied between experiments, but the inhibition of myelination by $\mathrm{CD}$ was consistent (Table 2). Cultures grown on laminin and treated with either 0.25 or 0.5 $\mu \mathrm{g} / \mathrm{ml} \mathrm{CD}$ were used for analysis of actin organization and myelinspecific protein and mRNA expression. 


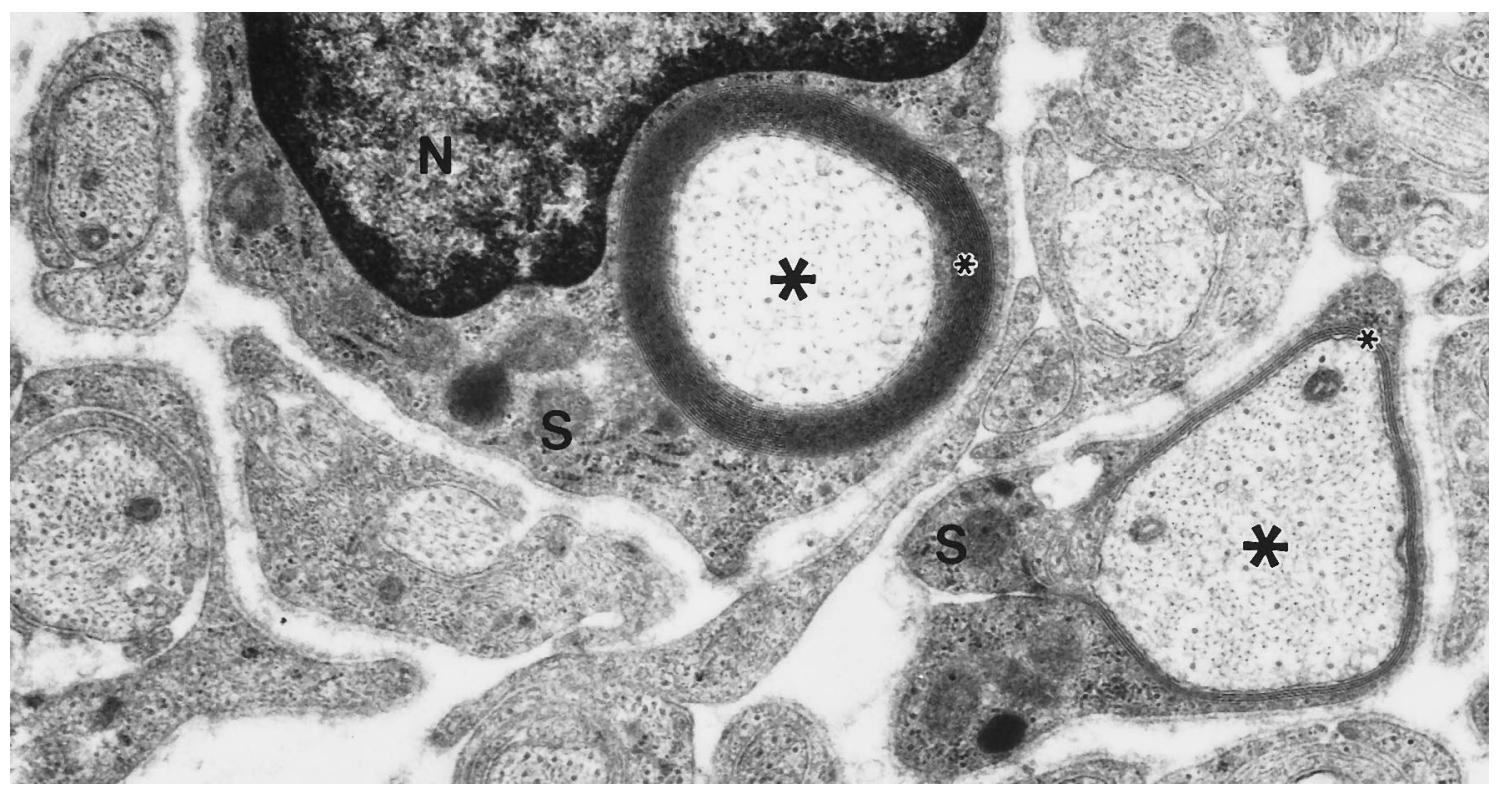

Figure 5. CD's inhibitory effect on myelination is reversible. Cultures were grown in myelination-permissive medium with $0.75 \mu \mathrm{g} / \mathrm{ml} \mathrm{CD}$ for $1 \mathrm{week}$ and then without $\mathrm{CD}$ for an additional week to determine whether drug toxicity prevented SC function. At removal of CD, SCs spiraled membranes around axons. An SC $(S)$, shown with its nucleus $(N)$, elaborated 20 myelin lamellae (small asterisk) around an axon (large asterisks), and an adjacent SC $(S)$ is beginning to myelinate. Magnification, $25,000 \times$.

\section{The inhibitory effects of CD are reversible}

To determine whether inhibition of myelination observed in cultures incubated in medium containing $\mathrm{CD}$ was attributable to cellular toxicity not apparent morphologically, a reversibility experiment was conducted. Cultures were treated with $0.75 \mu \mathrm{g} / \mathrm{ml}$ $\mathrm{CD}$ for $7 \mathrm{~d}$ and then maintained in myelination-permissive medium without $\mathrm{CD}$ for an additional $7 \mathrm{~d}$ before Sudan black staining and EM analysis. In these cultures, some SCs had formed myelin and many others had undergone changes in morphology, indicating that differentiation leading to myelination had begun (Fig. 5, Table 1). These changes in cell shape suggest that the SCs were viable and able to respond to myelination-permissive medium by differentiating and that with additional time, the number of myelin segments would have increased. Moreover, adding CD to already myelinated cultures did not lead to adverse changes in cellular morphology or loss of myelin (Table 1). This suggests that $\mathrm{CD}$ did not cause a general failure or disruption of cell metabolism, but rather, that when administered at a critical window of time, $\mathrm{CD}$ disrupted specific processes necessary for SC differentiation.

\section{CD disrupts actin organization}

The organization of actin in untreated and CD-treated cultures was ascertained using fluorochrome-conjugated phalloidin staining (Fig. 6). We observed an increasing amount of F-actin disrup- tion with increasing CD concentration. Actin distribution changed from a linear, continuous pattern of staining to an increasingly discontinuous staining pattern that was most noticeable in cultures treated with the higher CD concentration $(0.5 \mu \mathrm{g} / \mathrm{ml})$. In these cultures, phalloidan staining appeared as aggregates of varying size.

\section{CD prevents expression of myelin-specific proteins and mRNAs}

Expression of myelin-specific proteins was assessed by immunostaining cultures for the presence of three proteins, CNP, MAG, and $\mathrm{P} 0$, markers of promyelinating and myelinating SCs. The majority of SCs in cultures incubated with the lowest CD concentration used, $0.25 \mu \mathrm{g} / \mathrm{ml}$, did not express CNP, MAG, or P0 (Fig. 7). We occasionally observed limited expression and aberrant localization of MAG and P0 in SCs from CD-treated cultures. Expression of mRNAs encoding the myelin-specific proteins in myelinating and CD-treated cultures was determined by in situ hybridization. We were unable to detect myelin mRNAs in CDtreated cultures, whereas all three mRNAs were abundant in control cultures. This indicates that steady-state mRNA levels for $\mathrm{CNP}$, MAG, and $\mathrm{P} 0$ in CD-treated cultures were significantly lower than in myelinating cultures, even in the presence of axonal contact and adhesion to basal lamina.

\begin{tabular}{lclll}
\hline \multicolumn{2}{l}{ Table 2. Quantitation of myelin segments in SC-neuron cultures grown on laminin } & & \\
Condition & Experiment 1 & Experiment 2 & Experiment 3 & $2132 \pm 620$ \\
\hline $\mathrm{MM}$ & $1129 \pm 56$ & $888 \pm 203$ & $\mathrm{ND}$ & $5 \pm 2$ \\
$\mathrm{MM}+\mathrm{DMSO}^{*}$ & 1162,1260 & $\mathrm{ND}$ & $\mathrm{E}$ & $\mathrm{N}$ \\
$\mathrm{MM}+0.25 \mu \mathrm{g} / \mathrm{ml} \mathrm{CD}$ & $7 \pm 15$ & 0 & $\mathrm{ND}$ & $20 \pm 2$ \\
$\mathrm{MM}+0.5 \mu \mathrm{g} / \mathrm{ml} \mathrm{CD}$ & $3 \pm 6$ & $\mathrm{ND}$ & $\mathrm{ND}$
\end{tabular}

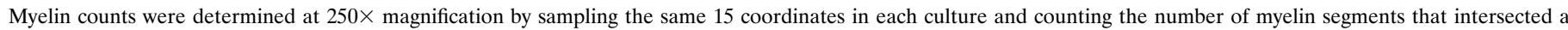
reference line. Mean and SEM of three to five cultures per group. *Only two cultures were counted. 

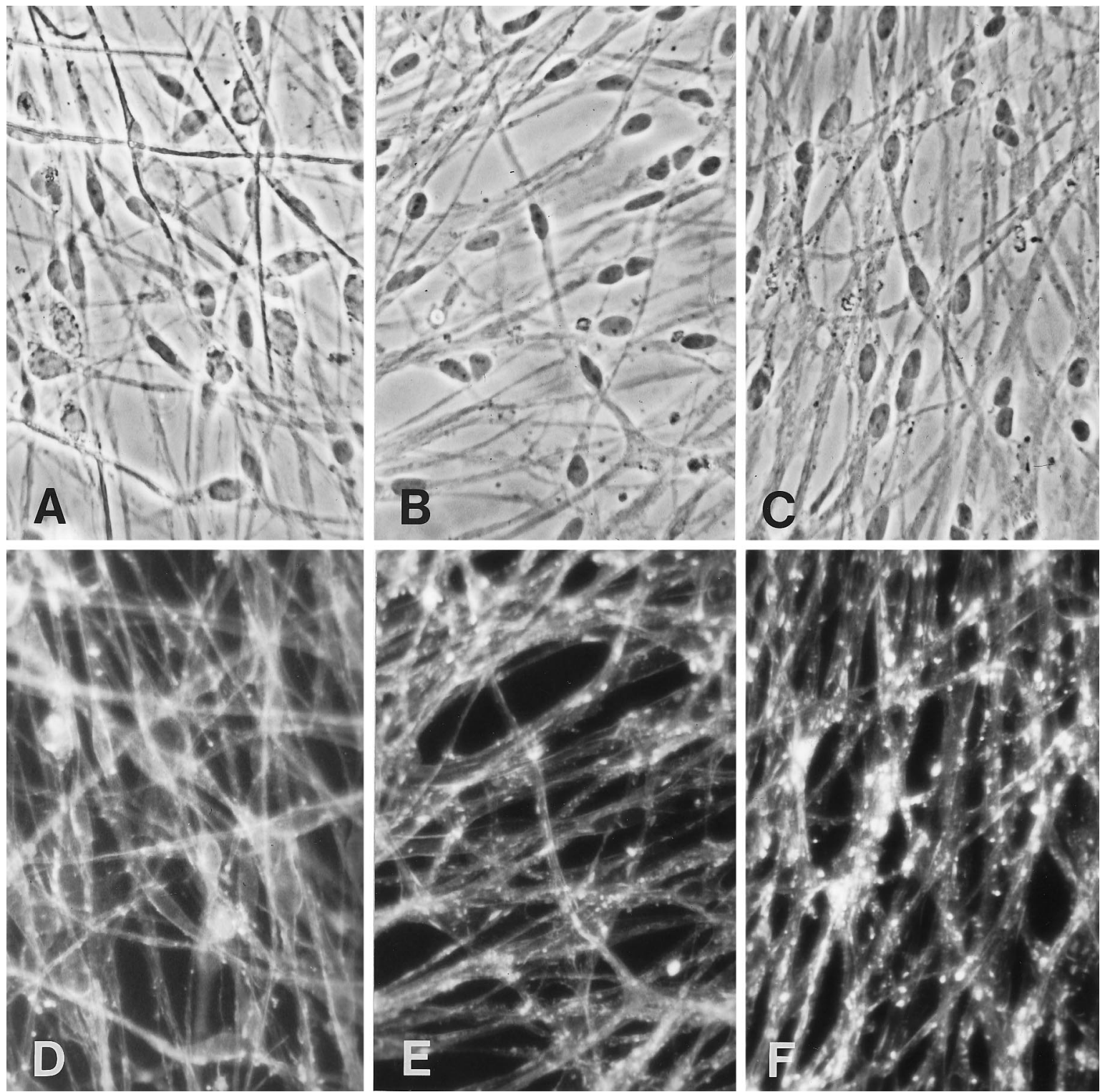

Figure 6. Actin organization is progressively disrupted with increasing $\mathrm{CD}$ concentrations. Phase $(A-C)$ and fluorescent $(D-F)$ micrographs of cultures grown on laminin for 1 week in myelination-permissive medium alone $(A, D)$ or with $0.25 \mu \mathrm{g} / \mathrm{ml} \mathrm{CD}(B, E)$, or $0.5 \mu \mathrm{g} / \mathrm{ml} \mathrm{CD}(C, F)$. Cultures were fixed and stained with rhodamine-conjugated phalloidin to visualize the distribution of actin filaments. In the absence of $C D$, phalloidin staining appears continuous and linear. In the presence of $\mathrm{CD}$, the pattern of staining becomes disrupted, appearing as large fluorescent aggregates. Magnification, $500 \times$.

\section{DISCUSSION}

Our results suggest that functional actin is needed during SC differentiation not only for changes in cell shape but also for abundant expression of myelin-specific mRNAs. The initial step in morphological differentiation, elongation, was inhibited only when higher $\mathrm{CD}$ concentrations $(0.75-1.0 \mu \mathrm{g} / \mathrm{ml})$ known to remove stress fibers in other cell types were used (Yahara et al., 1982). At lower CD concentrations $(0.25 \mu \mathrm{g} / \mathrm{ml})$, SC elongation and segregation of axons away from each other occurred, but ensheathment of axons in a 1:1 relationship and spiralization did not occur. Phalloidin staining of CD-treated cultures revealed that actin became increasingly disrupted and aggregated as CD concentration increased. At the time experiments began, all cultures had equal SC densities and SCs displayed a rounded morphology characteristic of their behavior in ascorbate-free medium, which allows SC proliferation but not differentiation (Eldridge et al.,
1987; Fernandez-Valle et al., 1993). Therefore, any morphological differentiation observed in CD-treated cultures developed during the incubation period in ascorbate and $\mathrm{CD}$. We hypothesize that at the lower CD concentration, sufficient F-actin formed to allow morphological differentiation to proceed up to, but not beyond, axon segregation.

In this study, SCs incubated with the lower CD concentration did not express myelin-specific mRNAs, but elongated and segregated axons, nonetheless. They did not, however, form 1:1 relationships with axons. Establishment of a one-to-one relationship between SC and axon is a necessary prelude to spiralization and compaction of myelin membranes. At this 1:1 stage, an individual SC contacts only one axon and forms an inner and outer mesaxon. This relationship essentially polarizes their membranes; the inner mesaxon contacts the axon and spirals around it, and the outer mesaxon contacts basal lamina (Bunge et al., 1989). Perturbation 

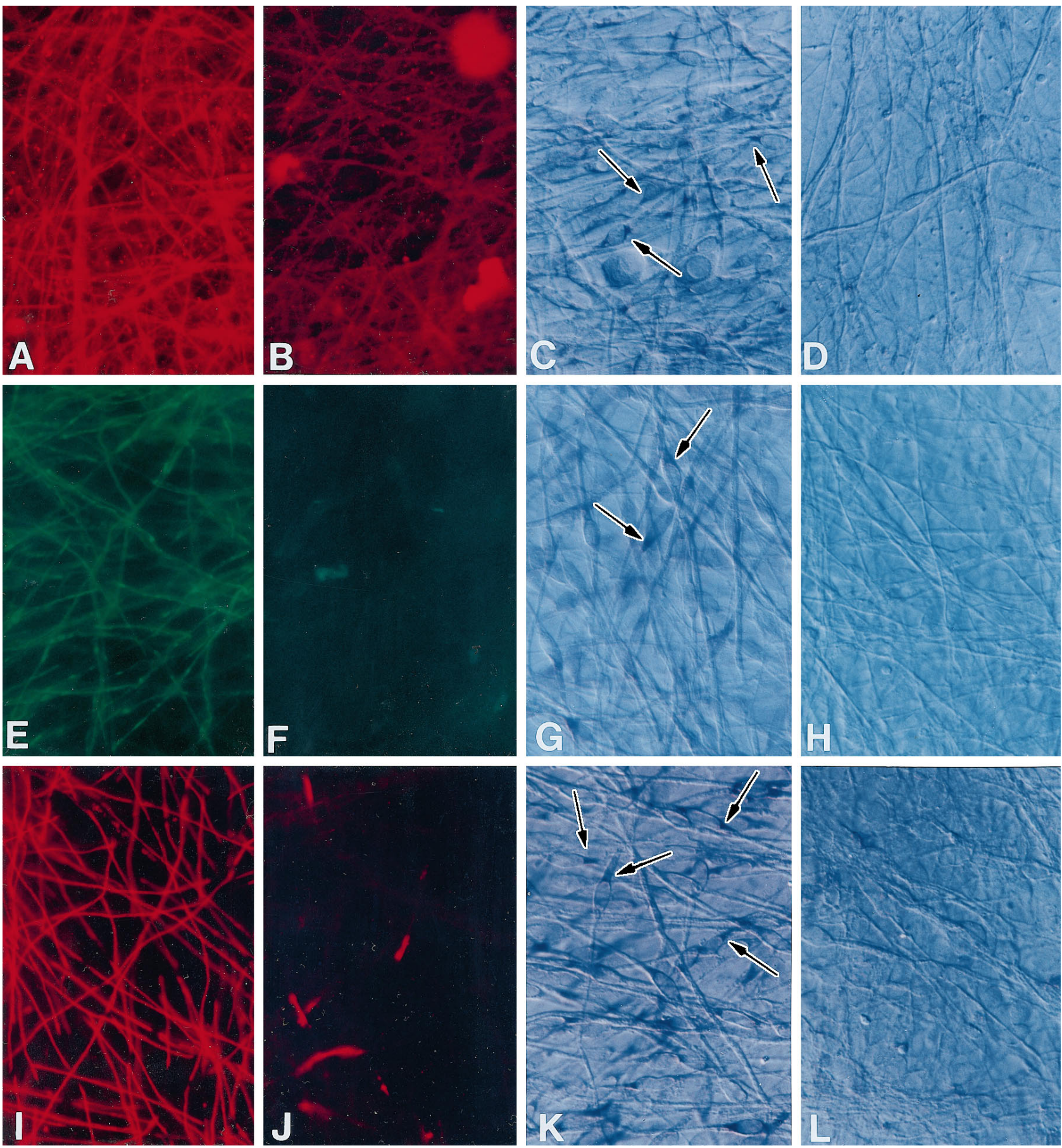

Figure 7. CD inhibits SC expression of myelin-specific proteins and mRNAs. Cultures grown in myelination-permissive medium alone $(A, C, E, G, I, K)$ or with $0.25 \mu \mathrm{g} / \mathrm{ml} \mathrm{CD}(B, D, F, H, J, L)$ were immunostained with antibodies against CNP $(A, B)$, MAG $(E, F)$, or P0 $(I, J)$ or processed for in situ hybridization using CNP $(C, D)$, MAG $(G, H)$, or P0 RNA probes $(K, L)$ to detect myelin-specific mRNAs. Arrows indicate positively stained Schwann cells. CNP, MAG, and P0 expression was greatly reduced in SCs cultured in the CD. In situ hybridization results indicated that mRNAs encoding the myelin-specific proteins were either not expressed or expressed at very low levels compared with control cultures. Sister cultures were hybridized with sense probes for each mRNA as negative controls. Magnification, $600 \times$.

of MAG expression in vitro results in the lack of 1:1 ensheathment and a failure to myelinate (Owens and Bunge, 1989, 1990, 1991; Owens et al., 1990). Our results are consistent with Owens' finding. CD-treated cultures that failed to express MAG and P0 did not form 1:1 relationships and failed to myelinate. Surprisingly, MAG knock-out mice develop peripheral myelin normally but suffer demyelination and axon degeneration during early adulthood (Li et al., 1994; Fruttiger et al., 1995), suggesting that other molecules can compensate for MAG during development of myelin, but that MAG has an essential function in maintaining axon/myelin integrity in the adult.

Three recent transgenic mice models lacking the transcription factors Krox-20 or SCIP provide indirect evidence for a role for MAG during 1:1 ensheathment (Topilko et al., 1994; Berming- 
ham, 1996; Jaegle et al., 1996). Myelination failed to occur in the mutants, and SCs were stalled at the 1:1 stage of differentiation. In each case, MAG was present at normal or slightly reduced levels, suggesting a strong correlation between the presence of MAG and achievement of one-to-one ensheathment of axons. P0 was not expressed in the mutants, and spiralization and compaction did not occur. P0 is believed to facilitate membrane compaction (Ranscht et al., 1987; Giese et al., 1992). Our data are consistent with the interpretation that sufficient F-actin was present in the SCs to commence morphological differentiation. However, the dearth of MAG and P0 mRNAs at the critical stage of differentiation led to an abrupt cessation of myelination.

It is unclear how disruption of actin polymerization dynamics by $\mathrm{CD}$ influences myelin-specific gene expression. Work by others has shown that $C D$ interferes with signal transduction from activated $\beta 1$ integrins in platelets (Lipfert et al., 1992). We demonstrated previously that $\mathrm{P} 0$ gene expression is linked to SC adhesion to basal lamina and that $\beta 1$ integrins are involved in binding basal lamina to the SC surface and are necessary for myelination to occur in vitro (Fernandez-Valle et al., 1993, 1994b). $\beta 1$ integrins are known to lead to induction of differentiation-specific genes in several cell types, including fibroblasts, monocytes, and mammary epithelial cells (Werb et al., 1989; Kornberg et al., 1991; Schmidhauser et al., 1992; Yurochko et al., 1992; Juliano and Haskill, 1993; Boudreau et al., 1995). In mammary epithelial cells, the hormone prolactin and extracellular matrix act in unison to stimulate expression of genes encoding milk proteins (Lin and Bissell, 1993). A matrix-sensitive response element exists in the $\beta$-casein promoter (Schmidhauser et al., 1992), and the function of a $\beta 1$ integrin appears necessary for induction of milk genes (Streuli et al., 1991). Similarly, a dual pathway involving axonderived and matrix-derived signals is necessary for maximum expression of myelin-specific genes in SCs. It is known that surface-bound, soluble axonal factors and cAMP activate myelin gene expression but that the level of expression is not as high as that induced by axon contact (Lemke and Chao, 1988) (for review, see DeVries, 1993; Bolin and Shooter, 1993). Therefore, we hypothesize that F-actin is part of a signal transduction pathway connecting basal lamina via $\beta 1$ integrins to induction of myelinspecific gene expression. Continued work in this area will elucidate the signal transduction pathway initiated at SC binding to basal lamina that undoubtedly merges with signals originating from the axon to cause full expression of the myelinating phenotype in SCs.

\section{REFERENCES}

Aguayo AJ, Charron L, Bray GM (1976a) Potential of Schwann cells from unmyelinated nerves to produce myelin: a quantitative ultrastructural and radiographic study. J Neurocytol 5:565-573.

Aguayo AJ, Epps J, Charron L, Bray GM (1976b) Multipotentiality of Schwann cells in cross-anastomosed and grafted myelinated and unmyelinated nerves: quantitative microscopy and radioautography. Brain Res 104:1-20.

Barth J, Ivarie R (1994) Polyvinyl alcohol enhances detection of low abundance transcripts in early stage quail embryos in a nonradioactive whole mount in situ hybridization technique. Biotechniques 17:324-326.

Bermingham JR, Scherer SS, O'Connell S, Arroyo E, Kalla KA, Powell FL, Rosenfeld MG (1996) Tst-1/Oct-6/SCIP regulates a unique step in peripheral myelination and is required for normal respiration. Genes Dev 10:1751-1762.

Bolin LM, Shooter EM (1993) Neurons regulate Schwann cell genes by diffusible molecules. J Cell Biol 123:237-243.

Boudreau N, Myers C, Bissell MJ (1995) From laminin to lamin: regulation of tissue-specific gene expression by the ECM. Trends Cell Biol 5:1-4.
Brockes JP, Fields KL, Raff MC (1979) Studies on cultured rat Schwann cells. I. Establishment of purified populations from cultures of peripheral nerve. Brain Res 165:105-118.

Bunge MB (1993) Schwann cell regulation of extracellular matrix biosynthesis and assembly. In: Peripheral neuropathy, 3rd Ed (Dyck PJ, Thomas PK, Griffin J, Low PA, Poduslo J, eds), pp 299-316. Philadelphia: Saunders.

Bunge RP, Bunge MB, Bates M (1989) Movements of the Schwann cell nucleus implicate progression of the inner (axon-related) Schwann cell process during myelination. J Cell Biol 109:273-284.

Carey DJ, Todd MS (1987) Schwann cell myelination in a chemically defined medium: demonstration of a requirement for additives that promote Schwann cell extracellular matrix formation. Dev Brain Res 32:95-102.

Carraway KL, Carraway CAC (1995) Signaling, mitogenesis and the cytoskeleton: where the action is. BioEssays 17:171-175.

Clark EA, Brugge JS (1995) Integrins and signal transduction pathways: the road taken. Science 26:233-239.

DeVries GH (1993) Schwann cell development. In: Peripheral neuropathy, Vol 1, 3rd Ed (Dyck PJ, Thomas PK, Griffin J, Low PA, Poduslo J, eds), pp 290-298. Philadelphia: Saunders.

deWebster H (1971) The geometry of peripheral myelin sheaths during their formation and growth in rat sciatic nerves. J Cell Biol 48:348-367.

Einheber S, Giancotti GF, Salzer JL (1993) Expression and distribution of the $\alpha 6 \beta 4$ integrin in myelinating Schwann cells. J Cell Biol 123:1223-1236.

Eldridge CF, Bunge MB, Bunge RP, Wood PM (1987) Differentiation of axon-related Schwann cells in vitro. I. Ascorbic acid regulates basal lamina assembly and myelin formation. J Cell Biol 105:1023-1034.

Eldridge CF, Bunge MB, Bunge RP (1989) Differentiation of axonrelated Schwann cells in vitro. II. Control of myelin formation by basal lamina. J Neurosci 9:625-638.

Feltri ML, Scherer SS, Nemni R, Kamholz J, Vogelbacker H, Scott MO, Canal N, Quaranta V, Wrabetz L (1994) Beta 4 integrin expression in myelinating Schwann cells is polarized, developmentally regulated and axonally dependent. Development 120:1287-1301.

Fernandez-Valle C, Fregien N, Wood PM, Bunge MB (1993) Expression of the protein zero myelin gene in axon-related Schwann cells is linked to basal lamina formation. Development 119:867-880.

Fernandez-Valle C, Gomez AM, Bunge MB (1994a) Expression of myelin-specific molecules in Schwann cell/sensory neuron cultures lacking functional actin. Soc Neurosci Abstr 20:707.

Fernandez-Valle C, Gwynn L, Wood PM, Carbonetto SC, Bunge MB (1994b) Anti- $\beta 1$ integrin antibody inhibits Schwann cell myelination. J Neurobiol 25:1207-1226.

Fruttiger M, Montag M, Schachner M, Martini R (1995) Crucial role for the myelin-associated glycoprotein in the maintenance of axon-myelin integrity. Eur J Neurosci 7:511-515.

Giese KP, Martini R, Lemke G, Soriano P, Schachner M (1992) Mouse $\mathrm{P}_{\mathrm{o}}$ gene disruption leads to hypomyelination, abnormal expression of recognition molecules, and degeneration of myelin and axons. Cell 71:565-576.

Gorman DS, Bunge MB (1988a) Myelination of axons by Schwann cells is F-actin dependent as determined by the use of cytochalasin. Soc Neurosci Abstr 14:425.

Gorman DS, Bunge MB (1988b) Functional actin is required for myelination of axons by Schwann cells. J Cell Biol 107:515a.

Gravel M, DeAngelis D, Braun PE (1994) Molecular cloning and characterization of rat brain $2^{\prime}, 3^{\prime}$-cyclic nucleotide $3^{\prime}$-phosphodiesterase isoform 2. J Neurosci 14:243-247.

Horwitz A, Duggan K, Buck C, Beckerle MC, Burridge K (1986) Interaction of plasma membrane fibronectin receptor with talin-a transmembrane linkage. Nature 320:531-533.

Jaegle M, Mandemakers W, Broos L, Zwart R, Karis A, Visser P, Grosveld F, Meijer D (1996) The POU factor Oct-6 and Schwann cell differentiation. Science 273:507-510.

Juliano RL, Haskill S (1993) Signal transduction from the extracellular matrix. J Cell Biol 120:577-585.

Kleitman N, Wood PM, Bunge RP (1991) Tissue culture methods for the study of myelination. In: Culturing nerve cells (Banker G, Goslin K, eds), pp 337-377. Cambridge, MA: MIT.

Kornberg L, Juliano RL (1992) Signal transduction from the extracellular matrix: the integrin-tyrosine kinase connection. Trends Pharmacol 13:93-95. 
Kornberg LJ, Earp HS, Turner CE, Prockop C, Juliano RL (1991) Signal transduction by integrins: increased protein tyrosine phosphorylation caused by clustering of $\beta_{1}$ integrins. J Cell Biol 88:8392-8396.

Lemke G, Axel R (1985) Isolation and sequence of a cDNA encoding the major structural protein of peripheral myelin. Cell 40:501-508.

Lemke G, Chao M (1988) Axons regulate Schwann cell expression of the major myelin and NGF receptor genes. Development 102:499-504.

Li C, Tropak MB, Gerlai R, Clapoff S, Abramow-Newerly W, Trapp B, Peterson A, Roder J (1994) Myelination in the absence of myelinassociated glycoprotein. Nature 369:747-750.

Lin CQ, Bissell MJ (1993) Multi-faceted regulation of cell differentiation by extracellular matrix. FASEB J 7:737-743.

Lipfert L, Haimovich B, Schaller MD, Cobb BS, Parsons JT, Brugge JS (1992) Integrin-dependent phosphorylation and activation of the protein tyrosine kinase pp125 $5^{\text {FAK }}$ in platelets. J Cell Biol 119:905-912.

Miyamoto S, Teramoto H, Coso OA, Gutkind JS, Burbelo PD, Akiyama SK, Yamada KM (1995) Integrin function: molecular hierarchies of cytoskeletal and signaling molecules. J Cell Biol 131:791-805.

Mochly-Rosen D (1995) Localization of protein kinases by anchoring proteins: a theme in signal transduction. Science 268:247-251.

Niessen CM, Cremona O, Daams H, Ferraresi S, Sonnenberg A, Marchisio PC (1994) Expression of the integrin $\alpha 6 \beta 4$ in peripheral nerves: localization in Schwann cells and perineural cells and different variants of the $\beta 4$ subunit. J Cell Sci 107:543-552.

Otey CA, Pavalko FM, Burridge K (1990) An interaction between $\alpha$-actinin and the $\beta 1$ integrin subunit in vitro. J Cell Biol 111:721-729.

Owens GC, Bunge RP (1989) Evidence for an early role for myelinassociated glycoprotein in the process of myelination. Glia 2:119-128.

Owens GC, Bunge RP (1990) Schwann cells depleted of galactocerebroside express myelin-associated glycoprotein and initiate but do not continue the process of myelination. Glia 3:118-124.

Owens GC, Bunge RP (1991) Schwann cells infected with a recombinant retrovirus expressing myelin-associated glycoprotein antisense RNA do not form myelin. Neuron 7:565-575.

Owens GC, Boyd CJ, Bunge RP, Salzer JL (1990) Expression of recombinant myelin-associated glycoprotein in primary Schwann cells promotes the initial investment of axons by myelinating Schwann cells. J Cell Biol 111:1171-1182.

Ranscht B, Wood PM, Bunge RP (1987) Inhibition of in vitro peripheral myelin formation by monoclonal anti-galactocerebroside. J Neurosci 7:2936-2947.

Ratner N, Elbein A, Bunge MB, Porter S, Bunge RP, Glaser L (1986) Specific asparagine-linked oligosaccharides are not required for certain neuron-neuron and neuron-Schwann cell interactions. J Cell Biol 103:159-170.
Salzer JL, Holmes WP, Colman DR (1987) The amino acid sequences of the myelin-associated glycoprotein: homology to the immunoglobulin gene superfamily. J Cell Biol 104:957-965.

Schaller MD, Borgman CA, Cobb BS, Vines RR, Reynolds AB, Parsons JT (1992) PP 125 FAK, a structurally distinctive protein tyrosine kinase associated with focal adhesions. Proc Natl Acad Sci USA 89:5192-5196.

Schmidhauser C, Myers CA, Sanzo KT, Bolton S, Bissell MJ (1992) A novel transcriptional enhancer is involved in the prolactin-and extracellular matrix-dependent regulation of $\beta$-casein gene expression. Mol Biol Cell 3:699-709.

Shaw LM, Messoer JM, Mercurio AM (1990) The activation dependent adhesion of macrophages to laminin involves cytoskeletal anchoring and phosphorylation of the $\alpha_{6} \beta_{1}$ integrin. J Cell Biol 110:2167-2174.

Sonnenberg A, Linders CJT, Modderman PW, Damsky CH, Aumailley M, Timpl R (1990) Integrin recognition of different cell-binding fragments of laminin (P1, E3, E8) and evidence that $\alpha 6 \beta 1$ but not $\alpha 6 \beta 4$ functions as a major receptor for fragment E8. J Cell Biol 110:2145-2155.

Strueli CH, Bailey N, Bissell MJ (1991) Control of mammary epithelial differentiation: basement membrane induces tissue-specific gene expression in the absence of cell-cell interaction and morphological polarization. J Cell Biol 115:1383-1395.

Topilko P, Schneider-Maunoury S, Levi G, Baron-van Evercooren A, Ben Younes Chennoufi A, Seitanidou T, Babinet C, Charnay P (1994) Krox-20 controls myelination in the peripheral nervous system. Nature 371:796-799.

Weinberg HJ, Spencer PS (1975) Studies on the control of myelinogenesis. I. Myelination of regenerating axons after entry into a foreign unmyelinated nerve. J Neurocytol 4:395-418.

Werb Z, Tremble PM, Behrendsen O, Crowley E, Damsky CH (1989) Signal transduction through the fibronectin receptor induces collagenase and stromelysin gene expression. J Cell Biol 109:877-889.

Woodley DT, Rao CN, Hassell JR, Liotta LA, Martin GR, Kleinman HK (1983) Interactions of basement membrane components. Biochim Biophys Acta 761:278-283.

Yahara I, Harada F, Sekita S, Yoshihira K, Natori S (1982) Correlation between effects of different cytochalasins on cellular structures and cellular events and those on actin in vitro. J Cell Biol 92:69-78.

Yurochko AD, Liu DY, Eirman D, Haskill S (1992) Integrins as a primary signal transduction molecule regulating monocyte immediateearly gene induction. Proc Natl Acad Sci USA 89:9034-9038. 